\title{
Calpain-5 gene expression in the mouse eye and brain
}

\author{
Kellie Schaefer ${ }^{1}$, MaryAnn Mahajan ${ }^{1}$, Anuradha Gore ${ }^{1}$, Stephen H. Tsang ${ }^{3}$, Alexander G. Bassuk ${ }^{4}$ \\ and Vinit B. Mahajan ${ }^{1,2^{*}}$
}

\begin{abstract}
Objective: Our objective was to characterize CAPN5 gene expression in the mouse central nervous system. Mouse brain and eye sections were probed with two high-affinity RNA oligonucleotide analogs designed to bind CAPN5 RNA and one scramble, control oligonucleotide. Images were captured in brightfield.

Results: CAPN5 RNA probes were validated on mouse breast cancer tumor tissue. In the eye, CAPN5 was expressed in the ganglion cell, inner nuclear and outer nuclear layers of the retina. Signal could not be detected in the ciliary body or the iris because of the high density of melanin. In the brain, CAPN5 was expressed in the granule cell layers of the hippocampus and cerebellum. There was scattered expression in pons. The visual cortex showed faint signal. Most signal in the brain was in a punctate pattern.
\end{abstract}

Keywords: CAPN5, Calpain, In situ hybridization, Retina, Brain, Gene expression

\section{Introduction}

Calpain-5 (CAPN5) is a member of the calpain family of calcium-activated proteases that target a variety of pathways to exert control over numerous processes, including tissue necrosis, cytoskeletal remodeling, cell-cycle control, cell migration, myofibril turnover, regulation of gene expression, apoptosis, long-term potentiation, and signal transduction [1]. Many eye-related pathologies are associated with increased calpain activity. These include retinal hypoxia [2-5], retinal degeneration [6, 7], retinal detachment [8], retinitis pigmentosa [9-11], and glaucoma [12, 13]. Increased calpain activity is also associated with neurological diseases including, Huntington's disease [14], Alzheimer's disease [15, 16], multiple sclerosis [17], and traumatic brain injury [18, 19]. Autosomal dominant neovascular inflammatory vitreoretinopathy (ADNIV) is caused by single point mutations in the CAPN5 gene (OMIM \#602537) [20-22], which causes the CAPN5 protease to become hyperactive. ADNIV patients experience sequential uveitis, retinitis

\footnotetext{
*Correspondence: vinit.mahajan@stanford.edu

1 Omics Laboratory, Department of Ophthalmology, Byers Eye Institute, Stanford University, Palo Alto, CA 94304, USA

Full list of author information is available at the end of the article
}

pigmentosa, retinal neovascularization, and proliferative retinopathy. Which ultimately leads to blindness [20]. Currently there is no treatment.

An important question to understanding how CAPN5 leads to disease is identifying which tissues CAPN5 is expressed in and the levels of CAPN5 in those tissues. Previous studies have used RT-PCR to detect relative levels of CAPN5 in human and rat brains, with results showing a wide expression profile in rat and human brains $[23,24]$. Others have used immunohistochemistry (IHC) to detect CAPN5 in the retina of mice, which showed expression varied based on the antibody used [20, 22, 25]. Although these were important initial studies, a more complete picture is needed to understand CAPN5 expression in the central nervous system. In situ hybridization (ISH) offers some advantages over RT-PCR and IHC. ISH allows for detecting mRNA levels in an intact tissue, something RT-PCR does not. This is more specific because it produces an image that differentiates between specific cell types within a tissue and even cellular compartments within a cell type. ISH can also complement IHC data by detecting mRNA expression whereas IHC detects protein expression. Additionally, while multiple antibodies are available for CAPN5, they have previously been shown to give different expression patterns $[22,25]$. 
For this reason, mRNA in situ hybridization experiments were performed to identify the expression of CAPN5 in the mouse eye and brain.

\section{Main text \\ Methods \\ Animal Care and euthanasia}

Ten-week-old C57BL/6 mice were procured from the Toronto Centre for Phenogenomics. Mice were housed in a standard $12 \mathrm{~h}$ light/dark cycle. Healthy mice were euthanized by lethal intraperitoneal injection of sodium pentobarbital. Once animals were deeply anesthetized, the thoracic cavity was opened by a ventral midline incision and a small cut in the right atrium was made for blood outflow. $10 \mathrm{~mL}$ of PBS was perfused by a $25 \mathrm{~g}$ needle through the left ventricle. Then perfusion of $10 \%$ buffered formalin was performed. Organs were harvested and fixed overnight at $4{ }^{\circ} \mathrm{C}$.

\section{Tissue description and treatment}

Tissue sections were cut on a Microm HM 355S microtome (ThermoFisher, Waltham, MA) to a thickness of 10 microns. Formalin-fixed paraffin-embedded sections from $\mathrm{C} 57 \mathrm{Bl} / 6$ mice were deparaffinized for $5 \mathrm{~min}$ in xylene, immersed in 100\% ethanol for 5 min then air-dried. Treatment was with Bond Epitope Retrieval Solution 2 (AR9640, Leica Biosystems, Buffalo Grove, IL) for $30 \mathrm{~min}$.

\section{In situ hybridization with LNA probes}

High-affinity RNA oligonucleotide analogs (Locked Nucleic Acid, LNA ${ }^{\mathrm{TM}}$, Exiquon, Denmark) were designed to bind CAPN5 RNA. The proprietary Exiquon LNA ${ }^{\mathrm{TM}}$ probe designer software was used to design custom probes to target CAPN5, while limiting non-specific binding. A probe cocktail of calpain-5 probe-1 (5DigN/ TGATACACAGCGGAAGTGGT) and calpain-5 probe-2 (5DigN/ACCAGAGGCAGAGTGTAACAGT) (probe cocktail), and a scramble-miR (5DigN/GTGTAACACGTCTATACGCCCA), were prepared according to the manufacturer's recommended conditions (Exiqon, Denmark), and each was labeled at the $5^{\prime}$ end with digoxigenin [26]. All experimental tissue sections were probed with a cocktail of both probes 1 and 2 .

\section{Hybridization and washing procedures}

Probes were resuspended in $10 \mu \mathrm{l}$ then diluted 1:25 in Enzo hybridization buffer (ENZ-33808, Enzo Life Sciences, Farmingdale, NY), placed on tissue sections, covered with polypropylene coverslips and heated to $60{ }^{\circ} \mathrm{C}$ for $5 \mathrm{~min}$, followed by hybridization at $37^{\circ} \mathrm{C}$ overnight. Sections were washed in intermediate stringency solution $\left(0.2 \times\right.$ SSC with $2 \%$ bovine serum albumin) at $55^{\circ} \mathrm{C}$ for $10 \mathrm{~min}$.

\section{Immunohistochemistry and color development}

Sections were treated with anti-digoxigenin-alkaline phosphatase conjugate (1:150 dilution in $\mathrm{pH} 7$ Tris buffer; Roche, Switzerland) at $37{ }^{\circ} \mathrm{C}$ for $30 \mathrm{~min}$. Development was carried out with NBT/BCIP (34042, ThermoFisher, Waltham, MA), closely monitored and stopped when the control sections appeared light blue. Development time with the chromogen was between 15 and $30 \mathrm{~min}$. Sections were counterstained with nuclear fast red (N3020, Sigma-Aldrich, St. Louis, MO) for 3-5 min, rinsed and mounted with coverslips.

\section{Imaging}

Brightfield images for Figs. 1 and 2a, b, f-i were extracted from Leica ScanScope XT slide scans (Leica Biosystems, Buffalo Grove, IL) or on Zeiss Axio A1 (Zeiss Microscopy, Germany). Images for Fig. 2c-e, j-m were taken on a brightfield microscope (Zeiss Microscopy, Germany). All images were saved in jpeg format.

\section{Results}

To better understand CAPN5 expression in the central nervous system, an in situ hybridization assay was developed. Two CAPN5 oligonucleotide probes were designed along with a negative control scramble oligonucleotide probe (Fig. 3a). To validate the assay, a cocktail of CAPN5 probes 1 and 2 were first applied to mouse breast cancer sections (determined histologically from a tumor), since calpain expression is linked to a variety of cancers [2729]. CAPN5 expression was detected in the cancerous tissue but not the normal tissue (Fig. 3b). No signal was observed using the scramble probe (data not shown).

Next, we studied CAPN5 expression in the retina (Fig. 1). Previously, we reported that protein expression detection varied depending on which antibody was used [20, 22, 25]. CAPN5 mRNA signal was detected in the ganglion cell, inner nuclear and outer nuclear layers of the retina. This corroborated with our most recent IHC data indicating that CAPN5 is expressed in all layers of the retina, even though the phenotype is largely restricted to the photoreceptors [25]. Signal was not detected in the lens or cornea (data not shown). Because of the high density of melanin in the ciliary body, iris, and $\mathrm{RPE}$, the in situ probes signal could not be ascertained, but previous IHC studies did not identify CAPN5 protein in these structures.

Punctate signal was seen in the hippocampus and cerebellum. In each of these sites, signal was localized to the granule cell layers. Specifically, CAPN5 signal was detected in CA3 and the dentate gyrus of the hippocampus. Scattered large neurons in pons also showed punctate signal. There appeared to be some faint signal in the visual cortex, and there was no signal detected in 

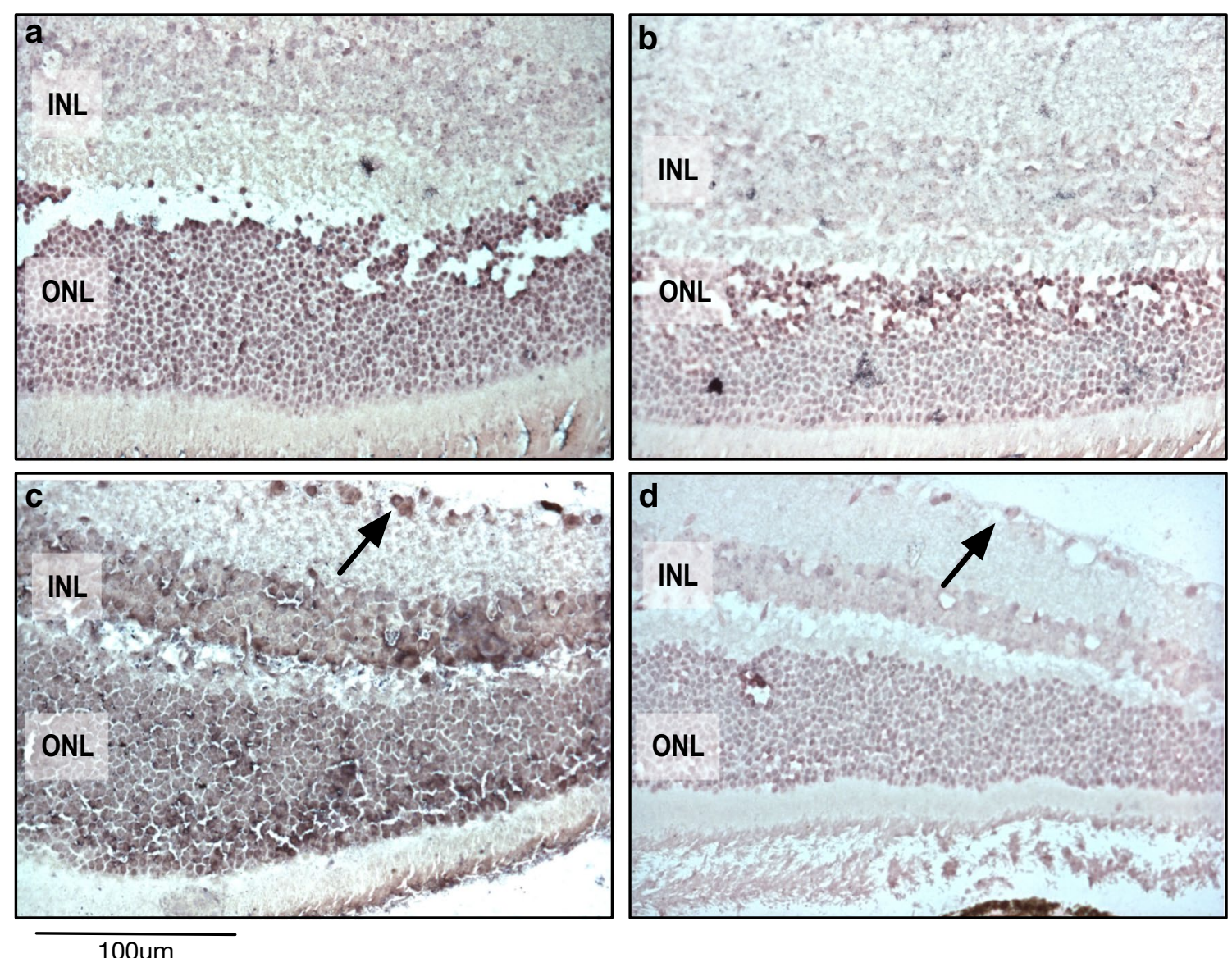

Fig. 1 CAPN5 mRNA expression in the retina. a Calpain 5 signal was detected in the inner nuclear layer (INL) and outer nuclear layer (ONL) of the central retina. b Scramble-miR (control) in a section adjacent to a. c Peripheral retina highlights CAPN5 signal in ganglion cell layer (arrow). d Scramble-miR (control) in a section adjacent to $\mathbf{c}$

the auditory cortex, hypothalamus or striatum (data not shown).

\section{Discussion}

Identifying target cells and cellular localization is important for gaining better insights into protein function when considering therapeutic intervention. Previous studies have reported a number of tissue types and cell types in the central nervous system to contain CAPN5 depending on the method used to detect it. RT-PCR showed CAPN5 is present at relatively high levels in the rat and human brain. It is the second highest expressed calpain in the rat brain, following CAPN2. Additionally, CAPN5 mRNA was detected ubiquitously in rat brain, but was only found in the frontal lobe, cerebellum, medulla, hypothalamus and thalamus in human brain. IHC studies revealed CAPN5 in the inner and outer segments (IS and OS), the inner and outer plexiform layers (IPL and OPL), inner nuclear layer (INL) and retinal ganglion cells (RGC), depending on the antibody used [20, 22, 25].

Studies in the EMBL-EBI gene expression database report relative tissue expression data collected from RNA-seq and microarray experiments [30, 31]. In mice, twelve studies investigating CAPN5 tissue expression were found on the EMBL-EBI database. In contrast to other data, these studies found a stark predominance of CAPN5 expression in brain tissue. The EMBL-EBI database included eight experimental datasets for human CAPN5 expression. Brain CAPN5 expression was also found in human datasets on EMBL-EBI, though at levels much more modest than in mice relative to other tissues investigated.

The results obtained in the current study are in agreement to previous IHC experiments. Both methods detected CAPN5 in retinal ganglion cells and the INL. However, our study also detected CAPN5 in the ONL, but not the IS and OS or the IPL and OPL. In agreement 

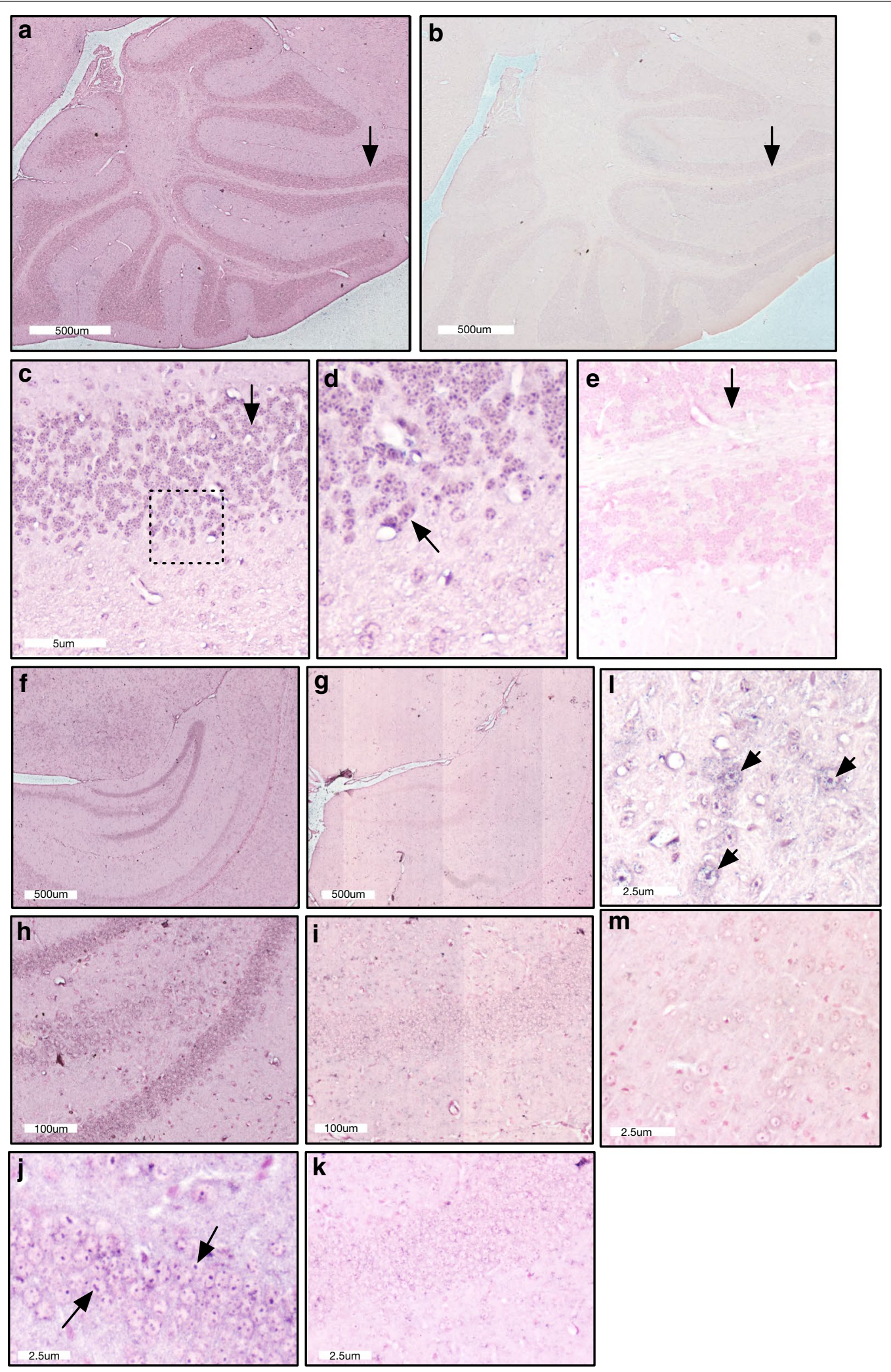
(See figure on previous page)

Fig. 2 CAPN5 mRNA expression in the brain. a-e CAPN5 mRNA expression in the cerebellum. a CAPN5 signal is concentrated in the granule cell layer (arrows) in the cerebellum. b Scramble-miR (control) in a section adjacent to $\mathbf{a}$. $\mathbf{c}$ Higher magnification of $\mathbf{a}$. $\mathbf{d}$ Higher magnification of $\mathbf{c}$. Note the punctate signal (arrow). e Scramble-miR (control) corresponding to $\mathbf{c}$. f-k CAPN5 mRNA expression in the hippocampus. $\mathbf{f}$ CAPN5 signal is concentrated in the granule cell layer in the hippocampus. $\mathbf{g}$ Scramble-miR (control) in a section adjacent to $\mathbf{f}$. $\mathbf{h}$ Higher magnification of $\mathbf{f}$. i Scramble-miR (control) corresponding to $\mathbf{h}$. $\mathbf{j}$ Calpain 5 signal seen in the granule cell layer at high magnification. Note the punctate signal (arrows). $\mathbf{k}$ Scramble-miR (control) in a section adjacent to j. I and $\mathbf{m}$ CAPN5 mRNA expression in the pons. I CAPN5 signal seen in larger neurons at high magnification. Note the punctate signal (arrows). $\mathbf{m}$ Scramble-miR (control) in a section adjacent to $\mathbf{I}$
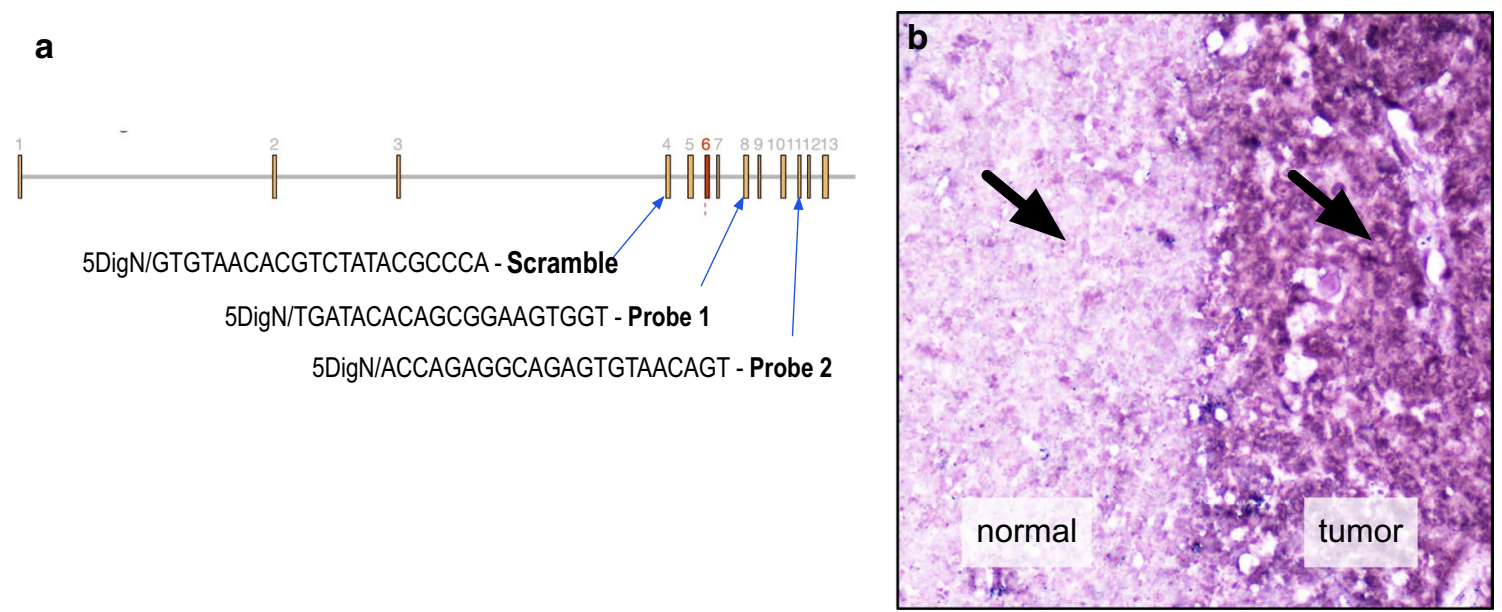

Fig. 3 Probes used for in situ assays. a The CAPN5 gene contains 13 exons (brown). The ADNIV associated mutations occur in exon 6 (red). The three probes correspond to three different spots within the CAPN5 gene. The control scramble probe corresponds to the scrambled version of a sequence in exon 4. Probe 1 corresponds to the indicated sequence in exon 8, and Probe 2 corresponds to the indicated sequence in exon 11 . $\mathbf{b}$ The probes were tested by application to normal tissue (left) and breast cancer tumor tissue (right)

with RT-PCR experiments, CAPN5 was detected in the cerebellum, specifically the granular cell layer. We also detected expression in the hippocampus and pons, but did not detect significant expression in any other regions.

Our results support our previous finding that CAPN5 may be playing a role in phototransduction. CAPN5 was detected in the INL, ONL and retinal ganglion cells. The INL is made up of the cell bodies of horizontal cells, amacrine cells and bipolar cells. The ONL contains the cell bodies of the two types of photoreceptors, rods and cones. Although we previously reported CAPN5 at the photoreceptor synapses, because in situ detects the mRNA of the protein, it's possible once CAPN5 is translated in the cell bodies, it is transported to the synapses. This hypothesis could also be true for CAPN5 expression in retinal ganglion cells, the cell type which forms the optic nerve.

The role of CAPN5 in the brain is less clear. The pons serves as a bridge between the cerebellum and forebrain. It controls many basic functions of the body including the basic senses, sleep, respiration and posture. The hippocampus is involved in memory, specifically longterm memory, while the cerebellum regulates motor movements, balance and speech. One hypothesis, based off the apparent role of CAPN5 in the eye, is that CAPN5 may play a role in signal transduction in the brain as well. This is supported by the fact that CAPN5 is seen at incredibly high levels in granule cells of the cerebellum, the most numerous type of neurons. Additionally, granule cells are believed to fine-tune inputs from the brain by allowing for combinatorial coding [32]. Further support for this hypothesis is the presence of CAPN5 in the dentate gyrus and CA3 subfield, which is the most interconnected region of the hippocampus. Nonetheless, patients with CAPN5 mutations to date do not display brain-related phenotypes, suggesting the effect of hyperactive CAPN5 is nondetrimental in the brain.

Although this study reported CAPN5 expression in the cerebellum, pons and hippocampus, ADNIV patient phenotypes are restricted to the eye. There may be excess calpain activity in the retina, due to the high level of calcium required for phototransduction; and the brain may be more resistant to CAPN5 damage since there are comparatively fewer cells in the granule cell layer expressing CAPN5. Another possibility is that CAPN5 has different substrates in the brain and eye, and one or more of the 
eye substrates may have a more detrimental effect when misregulated by a hyperactive CAPN5. Additional studies will need to be performed to determine the substrates of CAPN5.

Although some studies suggest ISH may give similar results to IHC, it seems to depend on the antibody used and is mainly analyzed in a present-or-not manner rather than in a qualitative manner [33-35]. Additionally, it is important to note that there may be differences in mRNA expression versus protein expression depending on the tissue. Therefore, in analyzing expression throughout a whole tissue, ISH in conjunction with IHC may give the most complete picture.

\section{Conclusions}

In the eye, CAPN5 mRNA was seen in ganglion cell, inner nuclear and outer nuclear layers of the retina. In the brain, signal was evident in the granule layers of the cerebellum and hippocampus and in scattered large neurons in pons. Our findings support the concept that CAPN5 may be playing a role in signal transduction in both the brain and eye. With this expression data in mind, future studies may begin to narrow down potential substrates of CAPN5, and better understand the underlying mechanism of its pathology. Ultimately, a better understanding of CAPN5 may provide useful drug targets as treatments for the many pathologies related to CAPN5.

\section{Limitations}

This study is limited to expression of CAPN5 in mice. There may be minor differences in human expression. This data and its relationship to CAPN5-associated diseases may be further interpreted once the substrates of CAPN5 have been identified. Future studies can examine other calpains in regions of the brain including a more detailed look at the cerebral cortex.

\footnotetext{
Abbreviations

CAPN5: calpain 5; IHC: immunohistochemistry; ISH: in situ hybridization; ADNIV: autosomal dominant neovascular inflammatory vitreoretinopathy; IS: inner segment; OS: outer segment; IPL: inner plexiform layer; OPL: outer plexiform layer; INL: inner nuclear layer; RGC: retinal ganglion cells.
}

\section{Authors' contributions}

KS and VBM designed and conducted the experiments and conceived the initial idea. All authors contributed equally in analyzing and interpreting the data. KS, MM, and VBM drafted the manuscript. All authors read and approved the final manuscript.

\footnotetext{
Author details

1 Omics Laboratory, Department of Ophthalmology, Byers Eye Institute, Stanford University, Palo Alto, CA 94304, USA. ${ }^{2}$ Palo Alto Veterans Administration, Palo Alto, CA, USA. ${ }^{3}$ Bernard and Shirlee Brown Glaucoma Laboratory, Department of Pathology and Cell Biology, Department of Ophthalmology, College of Physicians and Surgeons, Columbia University, New York, NY, USA.

${ }^{4}$ Department of Pediatrics, University of lowa, lowa City, IA, USA.
}

Acknowledgements

Phylogeny Inc. provided technical assistance.

\section{Competing interests}

The authors declare that they have no competing interests.

\section{Availability of data and materials}

Data generated or analyzed during this study are included in this published article. Any additional images generated but not shown during the current study are available from the corresponding author on reasonable request.

\section{Consent for publication}

Not applicable.

\section{Ethics approval and consent to participate}

The Institutional Animal Care and Use Committee (IACUC) approved all experiments. Rodents were used in accordance with the ARVO Statement for the Use of Animals in Ophthalmic and Vision Research, as well as the Policy for the Use of Animals in Neuroscience Research of the Society for Neuroscience.

\section{Funding}

KS is supported by NIH grant F31EY026789. VBM and AGB are supported by NIH Grants [R01EY026682, R01EY024665, R01EY025225, R01EY024698 and R21AG050437], and Research to Prevent Blindness (RPB), New York, NY. The Barbara \& Donald Jonas Laboratory of Regenerative Medicine and Bernard \& Shirlee Brown Glaucoma Laboratory are supported by the National Institute of Health [5P30EY019007, R01EY018213, R01EY024698, R21AG050437], National Cancer Institute Core [5P30CA013696], the Research to Prevent Blindness (RPB) Physician-Scientist Award, unrestricted funds from RPB, New York, NY, USA. SHT is a member of the RD-CURE Consortium and is supported by the Tistou and Charlotte Kerstan Foundation, the Schneeweiss Stem Cell Fund, New York State [C029572], the Foundation Fighting Blindness New York Regional Research Center Grant [C-NY05-0705-0312], the Joel Hoffman Fund, the Professor Gertrude Rothschild Stem Cell Foundation, and the Gebroe Family Foundation.

Role of the Sponsor: The funding organizations had no role in design and conduct of the study; collection, management, analysis, and interpretation of the data; preparation, review, or approval of the manuscript; and decision to submit the manuscript for publication.

\section{Publisher's Note}

Springer Nature remains neutral with regard to jurisdictional claims in published maps and institutional affiliations.

Received: 19 September 2017 Accepted: 10 November 2017 Published online: 21 November 2017

\section{References}

1. Potz BA, Abid MR, Sellke FW. Role of Calpain in pathogenesis of human disease processes. J Nat Sci. 2016;2(9):e218.

2. Tamada Y, Nakajima E, Nakajima T, Shearer TR, Azuma M. Proteolysis of neuronal cytoskeletal proteins by calpain contributes to rat retinal cell death induced by hypoxia. Brain Res. 2005;1050(1-2):148-55.

3. Hoang MV, Smith LE, Senger DR. Calpain inhibitors reduce retinal hypoxia in ischemic retinopathy by improving neovascular architecture and functional perfusion. Biochim Biophys Acta. 2011;1812(4):549-57

4. Nakajima E, Hammond KB, Rosales JL, Shearer TR, Azuma M. Calpain, not caspase, is the causative protease for hypoxic damage in cultured monkey retinal cells. Invest Ophthalmol Vis Sci. 2011;52(10):7059-67.

5. Azuma M, Hammond KB, Nakajima E, Shearer TR. Calpain protease causes hypoxia-induced proteolysis in cultured human retina. Curr Eye Res. 2014;39(4):421-4.

6. Azuma M, Shearer TR. The role of calcium-activated protease calpain in experimental retinal pathology. Surv Ophthalmol. 2008;53(2):150-63. 
7. Imai S, Shimazawa M, Nakanishi T, Tsuruma K, Hara H. Calpain inhibitor protects cells against light-induced retinal degeneration. J Pharmacol Exp Ther. 2010;335(3):645-52.

8. Chinskey ND, Zheng QD, Zacks DN. Control of photoreceptor autophagy after retinal detachment: the switch from survival to death. Invest Ophthalmol Vis Sci. 2014;55(2):688-95.

9. Nakajima E, David LL, Bystrom C, Shearer TR, Azuma M. Calpain-specific proteolysis in primate retina: contribution of calpains in cell death. Invest Ophthalmol Vis Sci. 2006;47(12):5469-75.

10. Kaur J, Mencl S, Sahaboglu A, Farinelli P, van Veen T, Zrenner E, Ekstrom P, Paquet-Durand F, Arango-Gonzalez B. Calpain and PARP activation during photoreceptor cell death in $\mathrm{P} 23 \mathrm{H}$ and S334ter rhodopsin mutant rats. PLoS ONE. 2011;6(7):e22181.

11. Shinde VM, Sizova OS, Lin JH, LaVail MM, Gorbatyuk MS. ER stress in retinal degeneration in S334ter Rho rats. PLoS ONE. 2012;7(3):e33266.

12. Huang W, Fileta J, Rawe I, Qu J, Grosskreutz CL. Calpain activation in experimental glaucoma. Invest Ophthalmol Vis Sci. 2010;51(6):3049-54.

13. Ryu M, Yasuda M, Shi D, Shanab AY, Watanabe R, Himori N, Omodaka K, Yokoyama Y, Takano J, Saido T, et al. Critical role of calpain in axonal damage-induced retinal ganglion cell death. J Neurosci Res. 2012;90(4):802-15.

14. Landles C, Sathasivam K, Weiss A, Woodman B, Moffitt H, Finkbeiner S, Sun B, Gafni J, Ellerby LM, Trottier Y, et al. Proteolysis of mutant huntingtin produces an exon 1 fragment that accumulates as an aggregated protein in neuronal nuclei in huntington disease. J Biol Chem. 2010;285(12):8808-23.

15. Getz GS. Calpain inhibition as a potential treatment of Alzheimer's disease. Am J Pathol. 2012;181(2):388-91.

16. Higuchi M, Iwata N, Matsuba Y, Takano J, Suemoto T, Maeda J, Ji B, Ono M, Staufenbiel M, Suhara T, et al. Mechanistic involvement of the calpain-calpastatin system in Alzheimer neuropathology. FASEB J. 2012;26(3):1204-17.

17. Das A, Guyton MK, Butler JT, Ray SK, Banik NL. Activation of calpain and caspase pathways in demyelination and neurodegeneration in animal model of multiple sclerosis. CNS Neurol Disord Drug Targets. 2008;7(3):313-20.

18. Yang J, Weimer RM, Kallop D, Olsen O, Wu Z, Renier N, Uryu K, TessierLavigne M. Regulation of axon degeneration after injury and in development by the endogenous calpain inhibitor calpastatin. Neuron. 2013;80(5):1175-89.

19. Liu S, Yin F, Zhang J, Qian Y. The role of calpains in traumatic brain injury. Brain Inj. 2014;28(2):133-7

20. Mahajan VB, Skeie JM, Bassuk AG, Fingert JH, Braun TA, Daggett HT, Folk JC, Sheffield VC, Stone EM. Calpain-5 mutations cause autoimmune uveitis, retinal neovascularization, and photoreceptor degeneration. PLoS Genet. 2012;8(10):e1003001.

21. Wert KJ, Skeie JM, Bassuk AG, Olivier AK, Tsang SH, Mahajan VB. Functional validation of a human CAPN5 exome variant by lentiviral transduction into mouse retina. Hum Mol Genet. 2014;23(10):2665-77.

22. Wert KJ, Bassuk AG, Wu WH, Gakhar L, Coglan D, Mahajan M, Wu S, Yang J, Lin CS, Tsang SH, et al. CAPN5 mutation in hereditary uveitis: the R243L mutation increases calpain catalytic activity and triggers intraocular inflammation in a mouse model. Hum Mol Genet. 2015;24(16):4584-98.
23. Waghray A, Wang DS, McKinsey D, Hayes RL, Wang KK. Molecular cloning and characterization of rat and human calpain-5. Biochem Biophys Res Commun. 2004;324(1):46-51.

24. Singh R, Brewer MK, Mashburn CB, Lou D, Bondada V, Graham B, Geddes JW. Calpain 5 is highly expressed in the central nervous system (CNS), carries dual nuclear localization signals, and is associated with nuclear promyelocytic leukemia protein bodies. J Biol Chem. 2014;289(28):19383-94.

25. Schaefer KA, Toral MA, Velez G, Cox AJ, Baker SA, Borcherding NC, Colgan DF, Bondada V, Mashburn CB, Yu CG, et al. Calpain-5 expression in the retina localizes to photoreceptor synapses. Invest Ophthalmol Vis Sci. 2016;57(6):2509-21.

26. Nuovo GJ. In situ detection of precursor and mature microRNAs in paraffin embedded, formalin fixed tissues and cell preparations. Methods. 2008;44(1):39-46.

27. Matena K, Boehm T, Dear N. Genomic organization of mouse Capn5 and Capn6 genes confirms that they are a distinct calpain subfamily. Genomics. 1998;48(1):117-20.

28. Hidalgo M, Saez ME, Martinez-Tello FJ, Moron FJ, Ferrero-Herrero E, Labalde-Martinez M, Rigopoulou D, Ballestin-Carcavilla C, Ruiz A, Royo $\mathrm{J}$, et al. Absence of allelic imbalance involving EMSY, CAPN5, and PAK1 genes in papillary thyroid carcinoma. J Endocrinol Invest. 2008;31(7):618-23.

29. Jonsson G, Staaf J, Vallon-Christersson J, Ringner M, Holm K, Hegardt C, Gunnarsson H, Fagerholm R, Strand C, Agnarsson BA, et al. Genomic subtypes of breast cancer identified by array-comparative genomic hybridization display distinct molecular and clinical characteristics. Breast Cancer Res. 2010;12(3):R42.

30. Petryszak R, Burdett T, Fiorelli B, Fonseca NA, Gonzalez-Porta M, Hastings E, Huber W, Jupp S, Keays M, Kryvych N, et al. Expression Atlas updatea database of gene and transcript expression from microarray- and sequencing-based functional genomics experiments. Nucleic Acids Res. 2014;42((Database issue)):D926-32.

31. European Molecular Biology Laboratory: Expression Atlas. https://www. ebi.ac.uk/gxa/home. 2017. Accessed 13 Sept 2017.

32. Marr D. A theory of cerebellar cortex. J Physiol. 1969;202(2):437-70.

33. Szczotka A, Stadejek T, Pejsak Z. A comparison of immunohistochemistry and in situ hybridization for the detection of porcine circovirus type 2 in pigs. Pol J Vet Sci. 2011;14(4):565-71.

34. Jiang H, Bai X, Meng F, Zhang X. Comparison of immunohistochemistry and mRNA in situ hybridization in detecting thyroid transcription factor-1 expression in non-small cell lung carcinomas tissue. Oncol Lett. 2015;10(6):3581-4.

35. Schmid E, Klotz M, Steiner-Hahn K, Konen T, Frisk AL, Schatz C, Krahn T, von Ahsen $\mathrm{O}$. Detection of MET mRNA in gastric cancer in situ. Comparison with immunohistochemistry and sandwich immunoassays. Biotech Histochem. 2017;1-11:425-35.

\section{Submit your next manuscript to BioMed Central and we will help you at every step:}

- We accept pre-submission inquiries

- Our selector tool helps you to find the most relevant journal

- We provide round the clock customer support

- Convenient online submission

- Thorough peer review

- Inclusion in PubMed and all major indexing services

- Maximum visibility for your research

Submit your manuscript at www.biomedcentral.com/submit 